\title{
GLAD!
}

Revue sur le langage, le genre, les sexualités

$03 \mid 2017$

Hétérosexualités

\section{Vers une théorie du roman postnormâle. Féminisme, réalisme et conflit sexuel chez Doris Lessing, Märta Tikkanen, Stieg Larsson et Virginie Despentes}

Résumé de thèse

Theorizing the Postnormale Novel. Feminism, Realism and Sexual Conflict in

the Works of Doris Lessing, Märta Tikkanen, Stieg Larsson and Virginie

Despentes

\section{Heta Rundgren}

\section{OpenEdition}

Édition électronique

URL : http://journals.openedition.org/glad/802

DOI : $10.4000 /$ glad.802

ISSN : 2551-0819

Éditeur

Association GSL

\section{Référence électronique}

Heta Rundgren, «Vers une théorie du roman postnormâle. Féminisme, réalisme et conflit sexuel chez Doris Lessing, Märta Tikkanen, Stieg Larsson et Virginie Despentes », GLAD! [En ligne], 03 | 2017, mis en ligne le 10 décembre 2017, consulté le 20 janvier 2021. URL : http://journals.openedition.org/glad/802 ; DOI : https://doi.org/10.4000/glad.802

Ce document a été généré automatiquement le 20 janvier 2021.

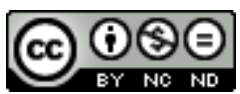

La revue GLAD! est mise à disposition selon les termes de la Licence Creative Commons Attribution Pas d'Utilisation Commerciale - Pas de Modification 4.0 International. 


\title{
Vers une théorie du roman postnormâle. Féminisme, réalisme et conflit sexuel chez Doris Lessing, Märta Tikkanen, Stieg Larsson et Virginie Despentes
}

\author{
Résumé de thèse \\ Theorizing the Postnormale Novel. Feminism, Realism and Sexual Conflict in \\ the Works of Doris Lessing, Märta Tikkanen, Stieg Larsson and Virginie \\ Despentes
}

Heta Rundgren

\section{RÉFÉRENCE}

Heta Rundgren. 2016. Vers une théorie du roman postnormâle. Féminisme, réalisme et conflit sexuel chez Doris Lessing, Märta Tikkanen, Stieg Larsson et Virginie Despentes. Thèse de doctorat en Littérature, sous la direction d'Anne Berger et de Tuija Pulkkinen, Université Paris 8 et Université de Helsinki, Finlande.

Entre littérature comparée et études de genre, cette thèse vise à théoriser ce que j'appelle le roman postnormâle à partir d'un corpus constitué d'une part d'un ensemble de romans européens contemporains [The Golden Notebook (1962) de Doris Lessing, Les Hommes ne peuvent être violés (1975) de Märta Tikkanen, la trilogie Millénium ou Les Hommes qui haïssent les femmes (2005-2007) de Stieg Larsson et Apocalypse bébé (2010) de Virginie Despentes], et d'autre part d'un corpus de textes théoriques, littéraires et féministes. J'y analyse la façon dont le roman postnormâle reprend le discours social concernant la «différence des sexes» pour s'adresser à un large public, tout en déplaçant subtilement les conventions réalistes afin d'inscrire dans l'écriture l'expérience du conflit sexuel du point de vue des femmes, voire des lesbiennes. Ma 
proposition de théorisation du roman postnormâle s'inscrit dans une perspective postmoderne : elle implique de suspendre, sans toutefois l'ignorer, la double question de la littérarité et de l'évaluation des œuvres, au profit d'une étude féministe de littérature en contexte. Enfin, du point de vue de la théorie féministe et queer, ce travail cherche à repenser les liens entre les notions de féminin et de queer, à l'aune des théories féministes et lesbiennes contemporaines.

2 Je procède en quatre étapes. D'abord, je cherche à rendre lisible un certain sexisme à l'œuvre dans les études littéraires, en étudiant notamment la façon dont les catégories de l'analyse littéraire s'appuient sur des métaphores et des métonymies genrées et sexistes. Il devient clair qu'une intervention postnormâle ne peut pas ne pas prêter attention au fait qu'il n'y a pas de neutre dans la langue française - ainsi, le masculin ne l'emporte pas sur le féminin dans cette étude, où certains pronoms mixtes sont également adoptés. Dans la deuxième partie, j'étudie le discours social qui s'est tissé autour de ce que j'appelle le conflit sexuel - un versant de la problématique de violences de genre et violences sexistes que le questionnement féministe fait émerger entre 1970 et aujourd'hui. On verra ici se dessiner un féminisme du roman postnormâle, dans sa façon de rendre compte des expériences du sexisme. Dans la troisième partie, pour traiter de la question de l'identification de genre comme crossidentification, j'examine comment le roman postnormâle met en mots le viol, qu'il rend lisible par le récit du contre-viol inversant les genres et la configuration « un fort vs une faible». Enfin, dans la dernière partie, j'étudie l'expérience du conflit sexuel comme négociation avec les récits normâles. J'interviens dans une certaine clôture référentielle où on revient à la théorie psychanalytique lacanienne, et où le conflit sexuel a un rapport avec la définition du pôle "féminin » comme manquant ou manqué. J'envisage une sortie de cette clôture à travers l'exploration de différentes pratiques d'entr'elles - pratiques féministes qui questionnent le normâle - dans le roman postnormâle et dans la théorie féministe et queer.

\section{INDEX}

Thèmes : Actualités

Keywords : feminist literary theory, queer theory, sexism, literary realism, feminist fiction

Mots-clés : théorie littéraire féministe, théorie queer, sexisme, réalisme dans la littérature, fiction féministe

\section{AUTEURS}

\section{HETA RUNDGREN}

Heta Rundgren a soutenu un doctorat en études de genre et littérature générale et comparée en 2016 à l'Université Paris 8 Vincennes-Saint-Denis, en cotutelle avec l'Université de Helsinki en Finlande. Elle s'intéresse tout particulièrement à la théorie littéraire féministe et queer, aux méthodologies interventionnistes en études de genre, à la pédagogie critique des normes, et elle 
a forgé le concept du postnormâle pour rendre visible comment la fiction et la théorie féministe inscrivent le conflit sexuel au cœur du roman réaliste contemporain. 